\title{
SHARING ECONOMY AND „INDUSTRY 4.0“ AS THE BUSINESS ENVIRONMENT OF MILLENNIAL GENERATION - a Marketing Perspective
}

\author{
Milan Brkljač, Tomislav Sudarević
}
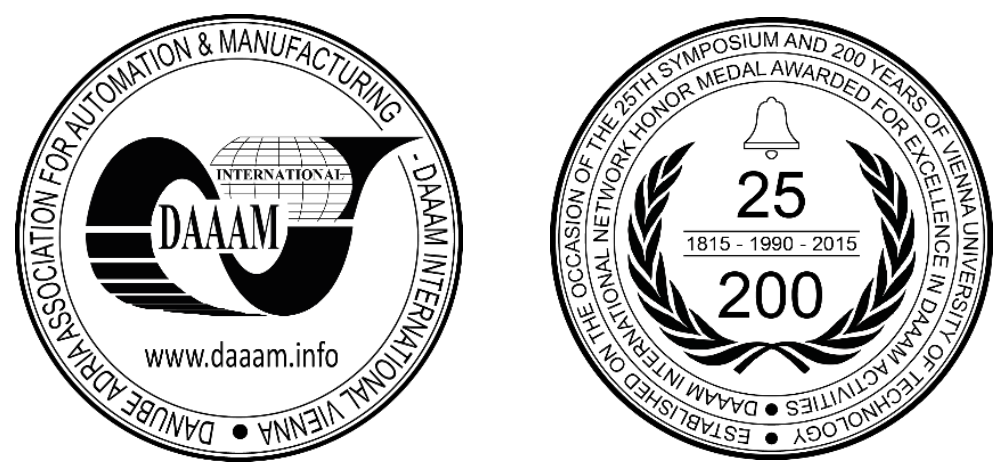

This Publication has to be referred as: Brkljac, M[ilan] \& Sudarevic, T[omislav] (2018). Sharing Economy and „Industry 4.0“ as the Business Environment of Millennial Generation - a Marketing Perspective, Proceedings of the 29th DAAAM International Symposium, pp.1092-1101, B. Katalinic (Ed.), Published by DAAAM International, ISBN 9783-902734-20-4, ISSN 1726-9679, Vienna, Austria DOI: $10.2507 / 29$ th.daaam.proceedings. 156

\begin{abstract}
For today's markets, dominated by new types of technologies, implementation of the principles of the "Industry 4.0" provides competitive advantage. Production processes strive toward automation and decrease of the work performed by humans. On the other hand, sharing economy is the increasingly represented form of the exchange in the leading world economies. Its roots are grounded in innovations and technologies that were brought by „Industry $4.0^{\prime \prime}$. It contributes to the efficiency in the consumption, but also in the production of goods and services, reduction of costs, amount of waste, and the development of a more humane society. Business environment that as an imperative has optimal allocation of the resources will shape the life and work of the millennials in the future. Therefore, it is particularly interesting what will be their perception of such environment that will bring restructuring of the workforce, employees and the customers. Comprehension of the relationship between the sharing economy and the "Industry 4.0" will provide an insight into the principles that could lead to these changes, while the conducted research of the behaviour of millennials in relation to the sharing economy will provide a possible way to comprehend their role in the "Industry 4.0".
\end{abstract}

Keywords: sharing economy; "Industry 4.0"; millennials; innovations; workforce

\section{Introduction}

Modern day markets are dynamic systems that call for permanent adaptation through different feedback mechanisms. A new type of industrialization that came into focus in recent years is the phenomenon known as the Industry 4.0. It has emerged as a result of synergetic effect of many technological breakthroughs that have been achieved in the last few decades, and has been appraised as a potential game changer in the creation of value and novel business models. On the other hand, today's customers, both consumers and the various industry entities, are underlining the need for customized products that will match specific requirements, enabling a more efficient utilization of users' resources and providing them at the end of the line with more personal satisfaction or profit. Prefix smart will play a key role in the realization of such ambitious goals and will affect elements of the entire value chain, starting from the production in smart factories, over smart logistics, up to smart products, services and processes. 
However, social aspects of the ongoing transformation will also have a significant impact on the pace of future innovations and development in such business environment. Therefore, it would be detrimental not to recognize potential trends and make the most of the social innovations that will emerge in the new environment. Advanced manufacturing, often recognized through additive manufacturing technologies, can be highlighted as one of the technologies that will provide higher levels of flexibility on the production side, but the development of the new social infrastructures that will support and facilitate important parts of the designed cyber-physical production systems will be one of the challenges in the deployment of the Industry 4.0, [1]. In many cases, workplaces will be moved outside of the factories or centralized organizations, making collaborative work of distributed entities vital for overall productivity. It is expected that the human work will include more active engagement, opening more place for personal creativity and workers' involvement. Therefore, understanding the needs and habits of the future workforce, and having insights into perceived experience of users in case of the business models (that are already based on some of the same key enabling technologies as the Industry 4.0) could prove to be useful in the design and planning of the social infrastructures and strategies. It will enable efficient interaction between humans and the new Industry 4.0 business environment. The ability of lifelong learning and opportunities for such activities will certainly remain to have significant role in the process of social changes, but for people it will be easier to accept certain models of behaviour that have silently become part of their everyday lives and which they have already potentially experienced as useful. Namely, sharing economy is a new form of the exchange in the leading world economies, which has brought different business models that involve significant levels of social interactions. It can be said that it contributes to the efficiency in the consumption, but also in the production of goods and services, reduction of costs, amount of waste, and the development of a more humane society. It is already present in different sectors of the economy, changing the traditional way how products and services are being consumed by the people. Similar to the Industry 4.0, sharing economy also benefits from the optimized decision-making and operations based on the data rich environment. Innovations and technologies that are brought by the Industry 4.0 are also foundations for efficient operation and acceptance of the sharing economy. In addition, it is expected that the generation of Millennials, people born between 1980 and 2000, will represent significant part of the workforce in the future business environment shaped by the principles and properties of the Industry 4.0 and the sharing economy. Therefore, their perception of the environment that will bring restructuring of the workforce, employees and the customers is important. In this paper we will try to understand some aspects of this complex relationship between the Industry 4.0 and the sharing economy by exploring their similarities and complementarities, on one hand, and by conducted research of the behaviour of millennials in relation to the acceptance and use of the sharing economy, on the other. Based on possible similarities, it will offer an additional insight into the role of Millennials in the Industry 4.0. Paper is organized as follows. In Section 2 we give an overview of the main concepts related to the Industry 4.0, sharing economy and the Millennials, goals and challenges that are put in front of the workforce and consumers. In Section 3 we describe a research aimed at understanding the acceptance of the principles of the sharing economy by the generation of Millennials. Corresponding results are presented and discussed in Section 4. In Section 5 we give concluding remarks and point out some of the future research directions.

\section{The new business environment of Millennial generation}

As it has already been mentioned, Millennials as a workforce will have to adapt to the change of traditional paradigm and pursue diverse career paths. Higher levels of automation will make redundant some of the roles that have been established in modern industries, enabling organizations to focus more on recruiting people with very specific skills and knowledge. Motivation of their employees will be essential component of overall productivity. In order to better understand nature of work in such environment we will make an overview of basic ideas and driving forces behind the Industry 4.0 and the sharing economy.

\subsection{Principles and technologies of the "Industry 4.0"}

The term Industry 4.0 was coined in an analogy to usual software versioning convention in which major updates are relatively rare and significant. As it has been discussed in [2], the term is often used to describe project of future development in which existence of a large application-pull is expected, resulting from the networked environment that will empower entities to pull customized products and services. At the same time it is also expected to exist an exceptional technology-push in the current industrial practice, through increased automation, digitalization, networking and miniaturization. It will have a significant impact on economic development, moving centers of profit from industrial companies to digital ones [3]. From the standpoint of innovative cyclical economic development [4], the next cycle characterized by nano-, bio-, information- and cognitive-technologies will bring technological displacement of human labor, with social consequences of the jobs loss for the middle class. Some of the previous trends that could be named as the predecessors of the Industry 4.0 are flexible specialization, just-in-time-production, and the development of technological parks, which are today enhanced by the modern information and production technologies. A review of the recent research that is related to important aspects of the Industry 4.0 has been presented in [5] and [6]. In [5], [6] there were identified five main research categories, which are related to general concepts and perspectives, cyber-physical systems, applications, key enabling technologies and the issues of interoperability. The need for comprehensive integration of all processes will influence standardization and interoperability. Three integration features that were identified as necessary in [7] are: a) horizontal integration, referring to integration of information systems related to production, logistics and marketing, within and between companies; b) vertical integration, referring to exchange of relevant information between different hierarchical levels; and c) an end-to-end integration throughout the engineering 
process, across a product's entire value chain, taking into account end-user requirements. An example of a multi-vendor initiative aimed towards higher interoperability between modules in an experimentally designed smart factory was presented in [8]. Smart factory model, described in [9], can be regarded as the value creation module at the highest aggregation level in the Industry 4.0, [10].

In its essence, Industry 4.0 specifically focuses on manufacturing in the current context, as opposed to the fourth industrial revolution that by some opinions should be associated with a systematic transformation of "civil society, governance structures, and human identity in addition to economic and manufacturing ramifications" [11]. However, as pointed out in [11], such conceptual division could be a matter of an academic dispute. Instead, the overall phenomenon should probably be viewed as a "confluence of trends and technologies", [12], arising from different novel approaches in which the main value drivers (quality, inventories, supply/demand match, time to market, services/aftersales, labor, assets utilization and resources/processes) are addressed. Through the content analysis that was performed by [13], there were identified fourteen technological trends that are supporting inevitable transition from the traditional manufacturing towards the Industry 4.0. Trends have been perceived as essential for the implementation of the twelve major design principles of the Industry 4.0, which were also identified the same literature review, and which are illustrated in Fig. 1.

One of the key enabling technologies, which is of particular importance, is the Internet of Things (IoT), [14], or more specifically Industrial IoT (IIoT). As can be seen from Fig. 1, it is strongly related to the design principles corresponding to the concepts of smart factories and smart products. Although IoT based technologies are usually considered as having specific roles in the implementation of the functional blocks that are responsible for the operations of measurement and control, e.g. as described in [15], their role in the Industry 4.0 goes beyond that, and also includes digital representations of products, processes, manufacturing infrastructure, and integration, [13]. Major challenges in application of IIoT are standardization, privacy issues, and security concerns, [16]. Some of the benefits provided by this technology are increased reliability, information aggregation and distributed processing, avoidance of dangerous events, active maintenance, data driven product design and marketing, higher production efficiency and improved recovery time.

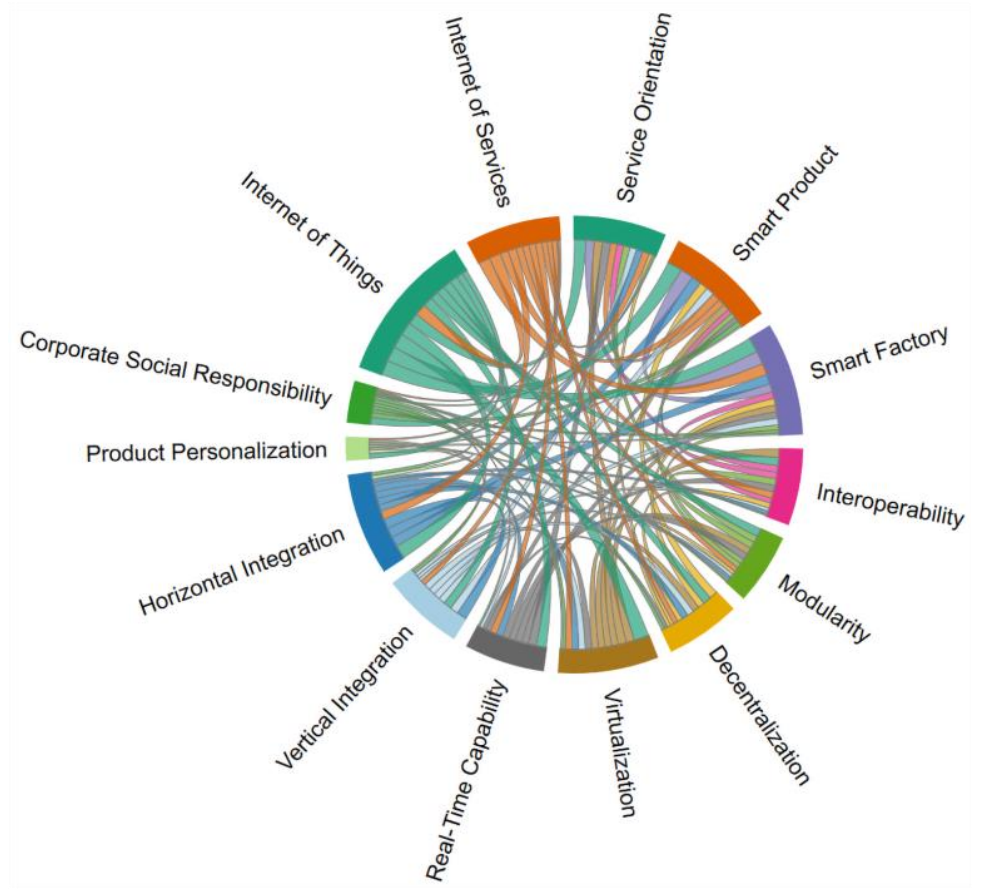

Fig. 1. Twelve design principles of the Industry 4.0 and the two major technological trends (Internet of Things and Internet of Services). Illustration is a chord diagram representing the frequencies of the joint appearance of the designated pairs of terms in the literature. It was generated using the results that were reported previously in the literature, the first part of the Table 1 in [13], where after selection of the 28 most influential journal papers and book chapters (among the pool of 178 research documents related to the Industry 4.0) a content analysis of selected documents was performed, and as a result a binary table was compiled with information about the appearance of the most prevailing terms in each of the selected documents. Width of the connection corresponds to the pair's relative frequency of appearance.

An overview of typical applications of IoT in the context of the Industry 4.0 was given in [17]. Significance of this technology for the development of Industry 4.0 is best illustrated by the decision of the authors of [7] to exclude from the review all sources in which definition of "the fourth industrial revolution" was not related to IoT or cyber-physical systems (CPS). It should be also mentioned that IoT technology includes different levels of abstraction, spanning a range of layers, from the physical level of sensors and actuators, over communication layers implementing different types of data transmission (wireless short range standards for indoor high data rate communications, low data rate communication over long range with high spatial coverage, or power line communications), layers performing data abstraction and analytics, up to the various digital services on top of the processing chain that as the final step include humane-machine interaction. 
Internet of Services (IoS), which was also highlighted in Fig.1, is technology oriented towards establishing a direct link between product consumers and manufacturers, through supplementary services. Usual use scenario is the one where the product is aware of its environment (smart product based on IoT) and constantly informs the provider of the service (manufacturer) about product usage, opening the possibility for a business model that is based on a product as a service. As a result, consumer can be charged in a customized way, based on the current product usage and short time behavior, while customer segmentation based on usage preferences collected during the adequately chosen time frame enables placement of specialized service packages or offers. As mentioned before, in addition to IoT and IoS, there are 12 more technological trends or drivers that are regarded as the most influential for the implementation of the design principles of the Industry 4.0. These are summarized in Fig. 2, in the same manner as in the case of the design principles in Fig. 1, with IoT and IoS appearing on both diagrams. It is interesting to note that although the pair IoT-IoS appears the same number of times in both Fig.1 and Fig.2, the ratio of the proportions of the circles corresponding to the IoT and IoS in Fig. 1 and Fig. 2 is different, due to the different number of the total pairs in which each term appears in the case of the design principles, Fig. 1, and the technology trends, Fig.2 (e.g. IoS in Fig. 1 is present in 51 pairs, compared to 32 pairs in Fig.2).

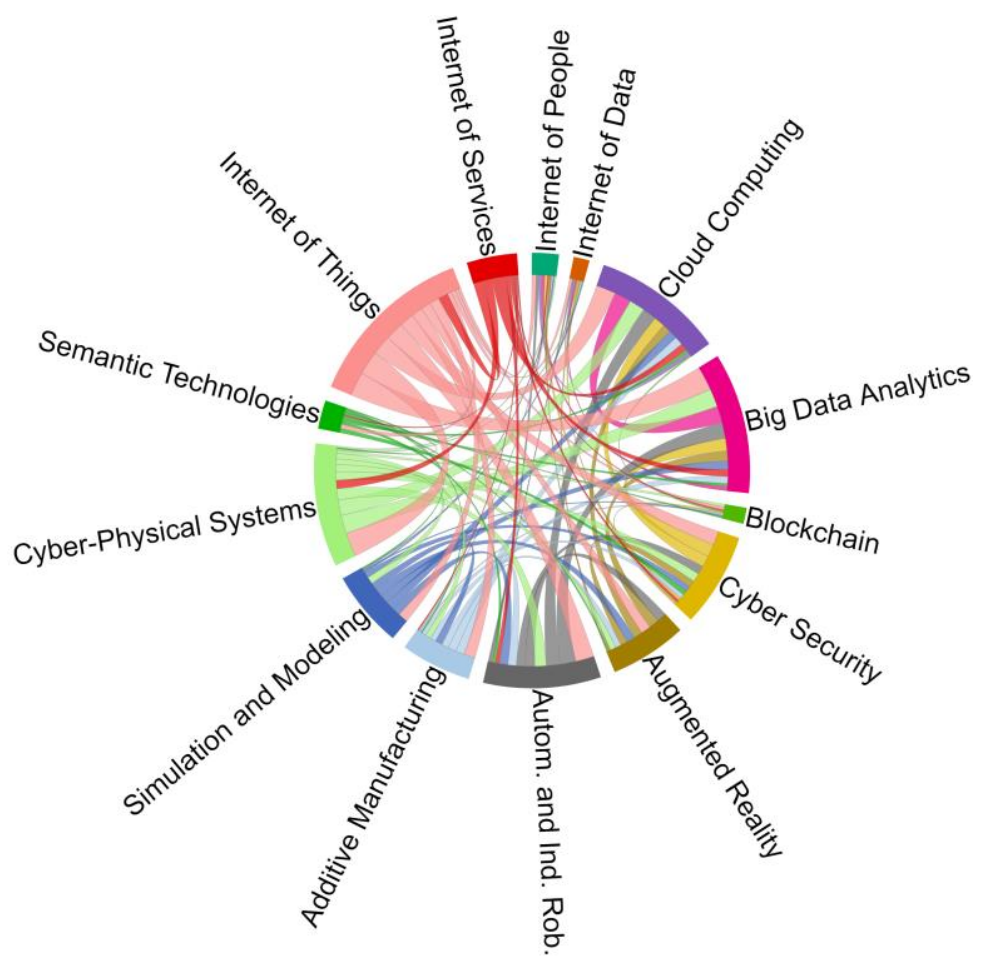

Fig. 2. Fourteen technological trends or drivers of the Industry 4.0 that are enabling implementation of the twelve major design principles of the Industry 4.0 (presented in Fig.1). Diagram illustrates how often particular pairs of terms that correspond to specific pairs of technologies jointly appear in the current research literature related to the Industry 4.0.

Diagram was generated using the same methodology as in Fig.1, based on the results reported in [13].

Beside technological trends that are shown in Fig. 2, authors of the study presented in [18] have also pointed out to some additional, complementary factors of influence, i.e. several driving aspects (organizational, operational, and innovation) that should be considered in the European strategic roadmaps towards successful accomplishment of the Industry 4.0 goals. Organizational aspects are related to the new forms of work and collaboration, [19], [18], one example being the so called "social factory" concept, [20], which puts an emphasis on a social network connecting people in the production, machines and software agents of the automated data analytics system, leading to the faster problem solving and more intuitive interaction between all parties, including machines. Operational driving aspects should enable organizations to stay competitive, e.g. through improvements at the operational level described in [21]. Innovation drivers will enable development of new business models, but also the development of "innovation networks", [18], which will only be a special instances of a larger ecosystem of many "collaborative networks", which have been foreseen by the authors of [22] as the places for value creation and materialization of the Industry 4.0. On the other hand, cross-linking of the value creation networks has been recognized, [10], as a promising approach for the realization of the closed-loop life cycles and industrial symbiosis. The former is expected to enable closer cross-company cooperation in trading and exchanging products, resources, and smart data on local level, providing them competitive advantage in the market, [23]. In the recent paper, [24], it was argued that the Industry 4.0, instead of being a major change of the existing paradigm, could be just an intermediate or meso revolution, i.e. a mechanism to create ever-growing and ever-changing markets in capitalism. Based on the analysis of the economy in the Republic of Korea, for the period between 2009 and 2014 , it was concluded that at the current stage, many national economies, including Korean, may not be well prepared to progress towards full implementation of the new paradigm, and that it is more likely that there is going to be a gradual transition, continuing the existing changes in capitalism. Industry 4.0 can be regarded as a move towards a more sustainable industrial value creation, [24], improving economic, social and environmental sustainability. 


\subsection{Sharing economy - new business paradigms in traditional industries}

Conditions for the emergence of the new business paradigms in traditional industries are made by development of technology and its increasingly significant influence on the economic relations between individuals. The appearance of these new paradigms have brought structural changes in the traditional business management styles, have changed the production process and communication between customers and service providers. The sharing economy is represent of one such paradigm. It developed from the consumers` aspiration to satisfy their needs for goods and services in the short run, with reduced amount of resources that are available to them. There are different definitions of term "sharing economy" in literature, nevertheless in most cases it is defined as "an economic system based on sharing underused assets or services, for free or for a fee, directly from individuals" [25], [26], [27]. Sharing assets through sharing economy market channels is alternative, ecologically friendly mode of consumption, which brings more value to people from ownership and reduces costs of usage of goods and services. One of the most important characteristics of sharing economy is immutability of ownership of assets used in consumption [28]. Instead, accessibility over goods and services is what consumers can get for predetermined amount of time, and significantly reduced amount of money.

Sharing economy is specific form of trade and sharing because there are no intermediaries between individuals in the exchange process. New technologies, first of all internet and online platforms, enable individual consumers to find each other and to make the transaction. The most common communication channels in sharing economy are online platforms, portals and applications which are managed by different companies, agents and brokers [29], [30]. Technology brought by Industry 4.0 has accelerated development of sharing economy worldwide. At the same time it enabled the creation of "critical mass" for sharing economy paradigm to live. Growth trend of usage of goods and services through sharing economy expands mostly from developed to developing countries and to underdeveloped countries as well. For example, according to available data, in US almost two thirds of residents say that they have used some kind of sharing economy services, and companies that enable interaction and communication between individual consumers had market value over 1 billion US dollars and 60.000 employees [27], [29], [31], [32], [33]. In countries where most residents cannot afford to buy most goods and services they need, sharing economy founds fertile ground to develop with significant speed. One of such striking examples is India, where, according to one research, about $90 \%$ of survey respondents state that they have used car sharing or drive sharing services [32]. Beside the rapid development of goods and services exchange in sharing economy market, the question that remains unanswered is what is about the trend of sharing economy acceptance and its growth in developing countries of Eastern Europe, such as the Republic of Serbia.

\subsection{Millennials - the workforce of the future}

How the generational groups will be defined to the great extent differs from the literature source. Generation represent group of people with similar age, which share identical years of experience through education and maturing. For that reason they share unique values and attitudes which makes the difference between generational groups [34]. Even though it is not precisely defined, it is quite often to find data in literature that millennial generation represent people born between years 1980 and 2000 [35], [36]. Any attempt to make general conclusions and to assign unique personality traits to all members of one generation undoubtedly lead to distorted view about individuals in one generation. Nevertheless, generalizations such as generational grouping has justification in practice because it is helpful for researchers to apprehend elements of the environment in which members of different groups are developing and to apprehend impact of those elements on future behaviour of individuals.

Some of the most commonly cited traits of millennial generation are: 1) They are special, and in focus of their parents, nation and world; 2) They were always subject of care and they have become the subject of widest youth protection movement in US history; 3) They are self-confident and optimistic, proud of potential and power of their generation; 4) They are team oriented, because they grew up with team sports and collective education; 5) They reach goals that are set and match the national standards in education; 6) Millennials feel a lot of pressure and strive to be excellent in everything they do; 7)

They are more prone to conventional way of thinking, as opposed to radical ones, because they feel that social order is established to help people [35]. Millennials, which are between 18 and 38 years old, with their traits and behaviour, have enormous impact and shape the world we live in. Their impact can be seen on the business organization, leisure time, social relations as well as mutual connectedness. This generation has changed the way of communication, reshaped traditional business models and redefined meaning of sociability in real life and online [37]. Certainly, there is a negative side of the medal, which is presented in following traits of millennials.

This generation is sometimes described as selfish, narcissistic, physically and emotionally connected with people in their circle of friends but disconnected from institutions and culture in the society [37]. As other generations before, Millennials request special conditions adjusted to their needs, in order to develop in working environment, business and private life. Transition from stage of education to stage of working age has major implications to creation of beliefs and activities about future career. According to authors Wendlandt and Rochlen, this process has three phases: anticipation (gathering information and evaluation which lead to attitudes creation); accommodation (individual is entering the company or working organization); and achievement (recognition of individual inside organization and decision making about staying in company) [36]. Even though millennial generation has entered their working age at the same time with economic downturn and crisis, technology has helped them to overcome this transitional period with fewer obstacles. In comparison to other generations, millennials have high level of education, they are prone to technology and highly mobile as workers [38]. Despite the view that the millennium generation wants a completely different working environment and do not have the same motivation to work as their predecessors, the results of one study show that their attitudes are 
identical with those of older generations. They want to be well-paid for their work, to work in an environment that provides support and to have a balance between their private and working life [38]. The only difference that has arisen in the relationship between generations is that millennials respect authority at work, but they also question it in terms of productivity and the way in which a particular job is done. When describing their ideal workplace, millennials use the following terms: "Family friendly", "culture friendly", "fun", "campus feel", "company events", "making a social difference", "listening leadership" [37].

When it comes to the way in which new knowledge is acquired, millennials oppose to formal instructions. They plan activities that rely on the method of trial and error, most of the knowledge they adopt is adopted from their peers, they value work in small groups and appreciate topics that are practically applicable, want to accept the risk but in a safe environment, and they are only interested in topics that they find valuable [39]. In order to attract and retain the millennial generation within the workforce, employers must adapt the working environment and the way of doing business in specific directions. Some of the recommendations to employers, that can be found in the literature are: The millennials need feedback - it is desirable to recognize the commitment and give them recognition; Millennials have realistic expectations of initial earnings and initial workplace, but expect rapid progress and development of new skills through work; They want a balance between work and private life; If all the conditions are optimal, millennials expect from the company they work for to be socially responsible [35].

\section{Acceptance and use of the sharing economy by Millennials - conducted research study}

Nowadays it can be often heard that the Millennial generation is the main pillar of the sharing economy paradigm. Their approach towards material goods, experiences and to life itself is changed in comparison to previous generations. Foremost under influence of diverse economic, social, and political crisis, during which they had grown-up and entered the adult age. Attitude that is expressed by the saying "you are what you possess", Millennials have gradually turned into "you are what you can access", [40]. Experience is the driving force of Millennials, and therefore ownership of material goods is ranked lower on the scale of their values. However, these two dispositions are not totally delineated, and their mixtures are still present, [41]. Social and economic crises, such was the one from 2008, had additional influence on the growth of the sharing economy, especially in developed countries. Young people were mostly forced to turn towards participation in the sharing economy, in order to compensate the loss of financial resources and allow themselves a more relaxed lifestyle during that period. Sensitivity of the question of renting a living space, as well the growth of the rate of unemployment, had significant effect on the acceptance of the sharing economy at that moment. As the consequences of the economic breakdown have been fading away, the question arises what is the acceptance of the sharing economy among the generation of Millennials, based on the values of culture and technology development that are promoted by this generation. Industry 4.0 will bring new opportunities for growth and progress through the use of technology.

Research of the behaviour of Millennials in relation to the acceptance and use of the sharing economy had several phases. The basic goal was to get an insight into factors that influence acceptance of the sharing economy by Millennials, in the business environment of the Industry 4.0. Attitudes of the Millennials regarding the question of the sharing economy use and acceptance were examined in the market of the Republic of Serbia, which is considered as a developing country, and in which sharing economy has just started to make a more significant growth and influence. Based on the previous research findings, available through the accessible literature sources related to the acceptance and use of the technology, as well as based on the literature related to the sharing economy, a specific survey was designed, as a basic research instrument. Survey consists of 28 questions that are exposed in the form of declarative sentences, with closed type answers that were organized in accordance with the Likert five-point scale, allowing individuals to express how much they agree or disagree with a particular statement (from the "totally disagree", up to the "totally agree").

Each of the questions was associated with one of the 7 predefined groups, corresponding to the factors that influence acceptance and use of the sharing economy. Sample was formed by participants from Serbia, of both sexes, aged between 18 and 38 years (millennial generation). Questionnaires were distributed in paper, as well as in electronic form, by the snowball sampling method. Number of correctly filled questionnaires that were taken into consideration and analysis for the needs of this paper was 106. Data collection was performed during the period between May and July 2018.

\section{Discussion and results}

\subsection{Organizing innovations - Millennials as the major workforce of the Industry 4.0}

In comparison to the approaches from the past, where organization knowledge was located exclusively at the top, in the Industry 4.0 it is expected that the relevant knowledge for solving organizational problems could be located anywhere within organization or an external network, [42]. In addition, instead of organizing routines, leading to the working environment in which individuals and organization do not share the same goals (or where there will be no humans in the organizing process), Industry 4.0 should be focused on organizing innovations, by enabling implementation of innovative ideas throughout organization, [42], using adequate analysis tools, [47], which can evaluate company's status.

The process of the relocation of the workforce from the unskilled to technically skilled labor was identified as the first obstacle to adoption of the Industry 4.0 in Denmark, [43]. Other obstacles that were also perceived by the representatives of the nineteen companies that were producing or using the Industry 4.0 technologies, [43], were: a) uncertainties related to the return-on-investment; b) security concerns; and c) lack of trust in the maturity of new technologies. 
It is certain that managerial aspects involved in the development of workforce competences will present new challenges for organizations adopting the Industry 4.0. As pointed out in [44], in order to deal with the decoupling of work and place, work and employment, and work and time, i.e. adapt to flexible work environment that will require new skills and competences in managing new technologies, companies will need to develop: a) technical; b) methodological (problem solving and decision-making); c) social (cooperation and communication with others); and d) personal competences (values, motivations and attitudes) of their employees. Identification of the new work roles of the existing jobs will be a first step in accomplishment of this goal, but the personal competencies are the ones that have been highlighted by [44] as the most critical success factor for implementation of the Industry 4.0.

Therefore, it would be of particular interest to gain some insight into the attitudes of the Millennial generation that is expected to be the major workforce, [19], in the period of transition towards the full implementation of the Industry 4.0 principles. Since the concept of the sharing economy exhibits similarities with the goals of the Industry 4.0 at different levels, as discussed in the next subsection, results obtained from the conducted study of the behaviour of Millennials in relation to the acceptance and use of the sharing economy could provide a possible way to comprehend their attitudes towards the flexible working environments and novel business models that are expected to emerge in the Industry 4.0, and which will be promoting changes in various organizations.

\subsection{Business model innovation in the Industry 4.0 - Qualitative comparison with the sharing economy}

Changes in the existing, well established business models that are expected to occur due to the change of the current paradigm, brought by the Industry 4.0, could be surprising. An example is the trend of the so called backshoring, which has been analyzed in the recent study presented in [45]. It is reported that the advanced manufacturing technologies of the Industry 4.0 are actually supporting the trend of the movement of the production back to the countries of business origin, which is becoming possible due to the increase in manufacture productivity. The same authors also suggest that the additional benefit, which is indirectly brought by the Industry 4.0 through the described backshoring, is the gain in flexibility due to the higher proximity of the local customers. This is in accordance with the general trend that the business models characterized by the competitiveness will require selling of functionality and flexibility of products, instead of "products" in traditional sense. In addition, organizations will be forced to change the way how they perceive their role in the market, going from the seller's into buyer's perspective.

In a way similar to the one in which some of the biggest companies of the sharing economy have conquered different sectors of the economy, starting as a small company that was exploiting disruptive innovations brought by the application of information and communication technologies, organizations of the Industry 4.0 will also open the space for smaller companies to more easily receive access to the benefits of the Industry 4.0 technologies, by promoting intercompany collaboration and communication in order to speed technology development, [43]. Therefore, there should be no surprise if some small or medium size company makes a big name by exploiting intercompany connectivity, which is considered as one of the three major dimensions of the Industry 4.0 in the case of the small and medium-sized enterprises (SMEs), [46]. According to the same authors, what business model elements (value creation, value capture, or value offer) will be innovated by some manufacturing SME in the Industry 4.0, it is expected to depend on the role that particular SME will have (user and/or provider of the Industry 4.0), but also to be influenced by the type of motivation for innovation of the business model (internal or external). Under business model innovation is considered change that goes beyond simple market adjustments, it attracts new customers, increases their loyalty, and reduces costs.

Considering parallels with the business models present in the sharing economy, it can be said that there is a great similarity in which the Industry 4.0 is expected to influence the value capture of the manufacturing SMEs, nicely summarized in Table 2 in [46], and the way in which the sharing economy platforms approach individual customers.

For example, payment methods are based on the pay-per-use or pay-per-feature strategy, there are also the same questions of the payment reliability, and automated invoices. On the other hand, customer interaction in both cases is based on the customer contact via digital platforms, which is eased through digital communication, there is also cost transparency, customization through co-design and co-engineering, movement of companies from product manufacturers to product providers, and in both cases risks and opportunities for customer retention are intensified. On the side of value offer, dominant type of value offers in the sharing economy are services, which are by their nature in most cases quite different from those offered by the manufacturing SMEs.

However, in both cases they are aimed at improving usual customer experience and customer's overall satisfaction, and by doing so share many of the Industry 4.0 technologies listed in Fig. 2. On the side of value creation, sharing economy is highly dependent on the partners and to some extent from suppliers, which is also expected to be the case in the Industry 4.0, where manufacturing SMEs will have to make innovative partnerships, increase standardization, perform virtual contacts, increase intercompany connectivity, and improve delivery reliability. In the similar way in which the sharing economy has made new types of jobs, Industry 4.0 will also create new job profiles, workplaces, but also create demand for workers with specific skills. Making a parallel with the changes that are expected to be exhibited by the product equipment, it can be said that the optimal allocation of the resources through energy savings, load balancing, fault resistance, fast access to relevant information, lower stocks, easier maintenance, and purchase of new equipment or retrofitting of the old one, are going to be common in both cases.

Finally, possibility that at some point there will appear a business model in which concepts of the sharing economy and the Industry 4.0 will coexist together should not be thrown away, since it is certain that many manufacturing companies (due to the market dynamics) will at some point have free production capacities that could be shared with others over specially designed collaborative networks. Development of such exchange platforms is certainly part of planned intercompany connectivity in the Industry 4.0, however the main question is: " 
What will be the prevailing attitude of the companies towards transparency of information that will be related to their operations?". This issue was also raised in [46], where some of the companies were strongly against any real-time information sharing, but where there was also a group of manufacturing SME companies that had a more proactive approach towards the connectivity issues.

\subsection{Acceptance and use of the sharing economy by Millennials}

(a)

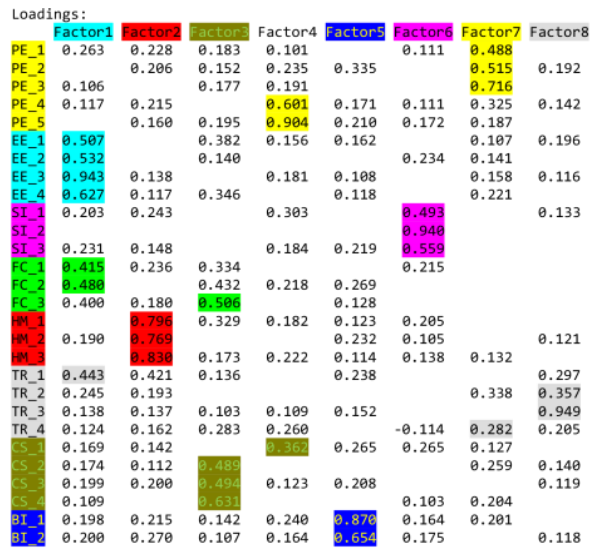

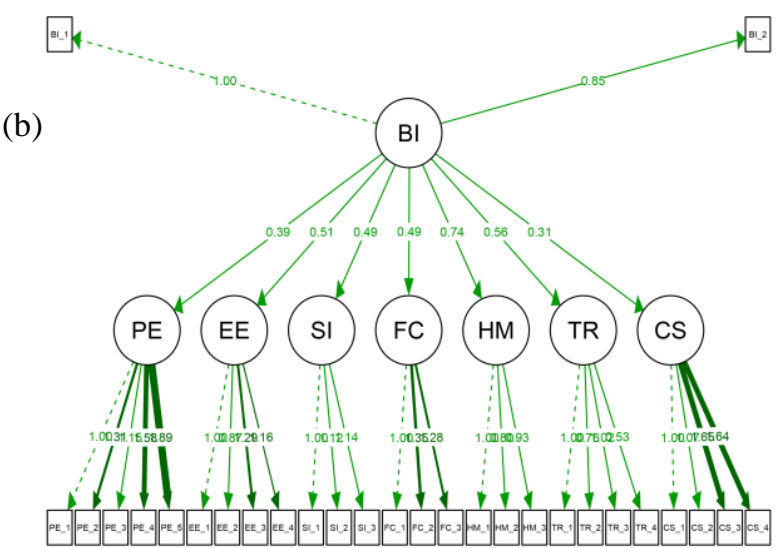

Fig. 3. Results of the exploratory (a) and confirmatory (b) factor analysis of the designed research survey with 28 items that was aimed at capturing intention of Millennials to accept and use the concepts of the sharing economy. Different colors in (a) denote groups of predefined questions describing different constructs that were modeled as latent variables

or factors in (b), and drawn as circles. Both analysis have confirmed initial assumption that manifestations of the respondents' latent intentions could be captured by the: performance expectancy (PE), effort expectancy (EE), social

influence (SI), facilitating conditions (FC), hedonic motivation (HM), trust (TR), culture of sharing (CS), and behavioral intention (BI) to use services of the sharing economy.

In comparison to the baseline model in which factor BI could be placed at the same level of hierarchy as the remaining factors and connected to a single higher factor that would in the same manner influence all other variables, proposed model in Fig. 3 (b) proved to be significantly different, and also achieving better fit (comparative fit index of 0.773 and RMSEA of 0.093 in comparison to 0.567 and 0.127 , respectively). Since the total number of respondents was 106 , it is expected that the model will further improve in the case of the bigger sample. It is interesting to note that the item CS_1 in Fig.3 (a) showed the highest level of association with the totally different factor from the rest of the items belonging to the same "culture of sharing" group.

In addition, it was also estimated as the least associated manifestation of the CS factor in Fig.3 (b). However, this comes as no surprise, since the nature of the statement proclaimed by the item is related to the intention of the respondent to appear as a service or product provider in the sharing economy, as opposed to the remaining three CS items that were dealing with the respondents' participation in the sharing economy from the perspective of the potential customer, which can be clearly seen from the original formulation of CS_1: "I would like to join the sharing economy market by offering my own material goods to others in consumption.". In Fig. 4 are presented estimated attitudes of Millennials in Serbia in relation to the acceptance and use of the sharing economy. They were obtained using the information collected through the conducted survey and by utilizing the model proposed in Fig. 2 (b). This is an ongoing research and presented results are therefore of somewhat limited scope, but the message they convey is that the prevailing attitude among millennials towards acceptance and use of the sharing economy is the one that is placed on the right half of the presented histograms, i.e. mostly positive.
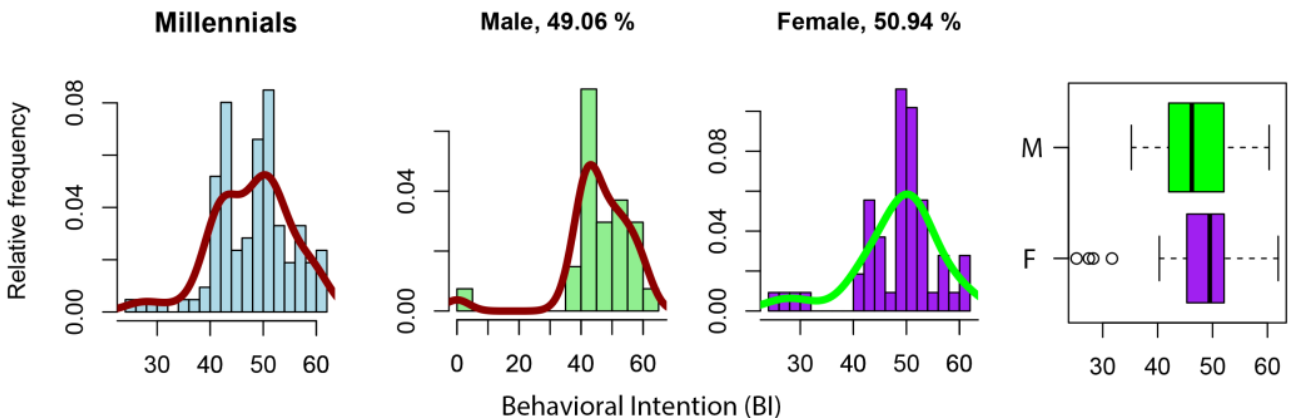

Fig. 4. Estimated intentions of Millennials to accept and use the sharing economy. 


\section{Concluding remarks}

Changes brought by the Industry 4.0 will require increased training of the future workforce, with more emphasis on the development of personal competences of the employees (values, motivations and attitudes) than it was the case in the past. In the first period of the gradual transition towards the full implementation of the design principles of the Industry 4.0, the generation of Millennials will be the one that will need to adapt to the flexible working environment and deal with the problem of organizing innovations in order to preserve companies' competitiveness. Paper has given an introductory overview of the Industry 4.0 and the sharing economy, their interaction, and the role of Millennials (as the major workforce of the Industry 4.0 in the near future), in both settings. Conducted research showed that Millennials generally have positive attitude towards acceptance and use of the sharing economy, Fig.4, which could imply that their perception of the new business environment that will be introduced by the Industry 4.0 will be also positive in overall. Such hypothesis could be grounded in a certain level of similarity which exists between the business models of the sharing economy, on one side, and the innovations of the business models that are expected to appear as a result of the future proliferation of the Industry 4.0, on the other. However, we should be aware of limitations in this research, which is present in the fact that it is hard to exactly predict Millennials' perception of the new business environment based only on the mentioned similarities between the sharing economy and the Industry 4.0. In addition, there is a need for repetition of the research comprising larger sample size, in several countries, in order to offset another limitation of the paper. Such extended research, with possible additional model improvements, could also serve as a basis for an independent research aimed exclusively towards the Industry 4.0, which would try to directly estimate Millennials' perception of the Industry 4.0 business environment. In our opinion this should be the next step, hence presented research study from the domain of the sharing economy could be regarded just as the initial effort in that direction.

\section{References}

[1] Kagermann, H.; Wahlster, W. \& Helbig, J. (2013). Recommendations for implementing the strategic initiative INDUSTRIE 4.0: securing the future of German manufacturing industry, Industrie 4.0 Working Group.

[2] Lasi, H.; Fettke, P.; Kemper, H. G.; Feld, T. \& Hoffmann, M. (2014). Industry 4.0. Business \& Information Systems Engineering, Vol. 6, No. 4, August 2014, 239-242, ISSN 1867-0202.

[3] Feshina, S.; Konovalova, O. \& Sinyavsky N. (2018). Industry 4.0 - transition to new economic reality, In: Industry 4.0: Industrial Revolution of the 21st Century, Popkova, E.; Ragulina, Y. \& Bogoviz, A. (Ed.), 111-120, Springer.

[4] Akaev, A. \& Rudskoi A. (2017). Economic potential of breakthrough technologies and its social consequences, In: Industry 4.0 - Entrepreneurship and structural change in the new digital landscape, 111-120, Springer.

[5] Lu, Y. (2017). Industry 4.0: A survey on technologies, applications and open research issues. Journal of Industrial Information Integration, Vol. 6, June 2017, 1-10, ISSN 2452-414X.

[6] Vieira, A.; Dias, L.; Santos, M.; Pereira, G. \& Oliveira, J. (2018). Setting an Industry 4.0 research and development agenda for simulation - a literature review. Int. J. of Simulation Modelling., Vol. 17, No. 3, 2018, ISSN 1726-4529.

[7] Liao, Y.; Deschamps, F.; Loures, E. \& Ramos, L. (2017). Past, present and future of Industry 4.0 - a systematic lit. review and research agenda prop. Int. J. of Prod. Res., Vol. 55, No. 12, March 2017, 3609-3629, ISSN 1366-588X.

[8] Weyer, S.; Schmitt, M.; Ohmer, M. \& Gorecky, D. (2015). Towards Industry 4.0 - standardization as the crucial challenge for highly modular, multi-vendor production systems, 15th IFAC Symp. on Inf. Control Problems in Manufacturing, ISSN 2405-8963, Vol. 48, No. 3, Dolgui, A.; Sasiadek J. \& Zaremba, M. (Ed.), pp. 579-584, Ontario.

[9] Chen, B.; Wan, J.; Shu, L.; Li, P.; Mukherjee, M. \& Yin, B. (2018). Smart factory of Industry 4.0: key technologies, application case, and challenges. IEEE Access, Vol. 6, 6505-6519, ISSN 2169-3536.

[10] Stock, T. \& Seliger, G. (2016). Opportunities of sustainable manufacturing in Industry 4.0. Procedia CIRP, Vol. 40, 536-541, ISSN 2212-8271.

[11] Sung, T. (2018). Industry 4.0: a Korea perspective. Techn. For. and Soc. Change, Vol. 132, 40-45, ISSN 0040-1625.

[12] Baur, C. \& Wee, D. (2015). Manufacturing's next act. McKinsey and Company, June 2015, 1-50.

[13] Ghobakhloo, M. (2018). The future of manufacturing industry: A strategic roadmap toward Industry 4.0. Journal of Manufacturing Technology Management, Vol. 29, No. 6, May 2018, 910-936, ISSN 1741-038X.

[14] Trappey, A.; Trappey, C.; Govindarajan, U. \& et al. (2017). A review of essential standards and patent landscapes for the Internet of Things: a key enabler for Industry 4.0. Adv. Eng. Informatics, Vol. 33, 208-229, ISSN 1474-0346.

[15] Daponte, P.; Lamonaca, F.; Picariello, F.; De Vito, L.; Mazzilli, G. \& Tudosa, I. (2018). A survey of measurement applications based on IoT, Workshop on Metrology for Industry 4.0 and IoT, 16-18 April 2018, Italy, ISBN 978-15386-2497-5, pp. 157-162, IEEE, Brescia, 10.1109/METROI4.2018.8428335.

[16] Karacay, G. \& Aydin, B. (2018). Internet of things and new value proposition, In: Industry 4.0: Managing The Digital Transformation, Ustundag, A. \& Cevikcan, E. (Ed.), 173-185, Springer, ISBN 978-3-319-57870-5, Turkey.

[17] Zhong, R.; Xu, X.; Klotz, E. \& Newman, S. T. (2017). Intelligent manufacturing in the context of Industry 4.0: a review. Engineering, Vol. 3, No.5, October 2017, 616-630, ISSN 2095-8099.

[18] Santos, C.; Mehrsai, A.; Barros, A.; Araújo, M. \& Ares, E. (2017). Towards Industry 4.0: An overview of European strategic roadmaps. Procedia Manufacturing, Vol. 13, June 2017, 972-979, ISSN 2351-9789.

[19] Baldassari, P. \& Roux, J. (2017). Industry 4.0: Preparing for the future of work. People \& Strategy: journal of the Human Resource Planning Society, Vol. 40, No. 3, summer 2017, 20-23, ISSN 1946-4606. 
[20] Kassner, L.; Hirmer, P.; Wieland, M.; Steimle, F.; Königsberger, J. \& Mitschang, B. (2017) The social factory: connecting people, machines and data in manufacturing for context-aware exception escalation. In Proceedings of the 50th Hawaii Int. Conf. on System Sciences. ISBN 978-0-9981331-0-2, pp. 1673-1682, HICSS, Honolulu.

[21] Davies, R.; Coole, T. \& Smith, A. (2017). Review of socio-technical considerations to ensure successful implementation of Industry 4.0. Procedia Manufacturing, Vol. 11, 1288-1295, ISSN 2351-9789.

[22] Camarinha-Matos, L.; Fornasiero, R. \& Afsarmanesh, H. (2017). Collaborative networks as a core enabler of Industry 4.0, In: Collaboration in a data rich world - 18th IFIP WG 5.5 Working Conference on Virtual Enterprises, Camarinha-Matos, L.; Afsarmanesh, H. \& Fornasiero R. (Ed.), 3-17, Springer, ISBN 978-3-319-65151-4, Italy.

[23] Chertow, M. (2007). "Uncovering" industrial symbiosis. Journ. of Ind. Eco., Vol. 11, No.1, 11-30, ISSN 1530-9290.

[24] Kim, J. (2018). Are countries ready for the new meso revolution? Testing the waters for new industrial change in Korea. Technological Forecasting and Social Change, Vol. 132, July 2018, 34-39, ISSN, 0040-1625.

[25] Hwang, J. \& Griffiths, M. (2017). Share more, drive less: Millennials value perception and behavioral intent in using collaborative consumption services. Journal of Consumer Marketing, Vol. 34, No. 2, 132-146, ISSN 0736-3761.

[26] Hamari, J.; Sjöklint, M. \& Ukkonen, A. (2015). The sharing economy: why people participate in collaborative consumption. Journal of the Association for Information Science and Technology, Vol.67, 1-13, ISSN 2330-1643.

[27] Möhlmann, M. (2015). Collaborative consumption: determinants of satisfaction and the likelihood of using a sharing economy option again. Journal of Consumer Behaviour, Vol. 14, No. 3, 193-207, ISSN 1479-1838.

[28] Bardhi, F. \& Eckhardt, G. (2012). Access-based consumption: the case of car sharing. Journal of Consumer Research, Vol. 39, No. 4, 881-898, ISSN 0093-5301.

[29] Ferrell, O.; Ferrell, L. \& Huggins, K. (2017). Seismic shifts in the sharing economy: shaking up marketing channels and supply chains. Journal of Marketing Channels, Vol. 24, No. 1-2, 3-12, ISSN 1540-7039

[30] Puschmann, T. \& Alt, R. (2016). Sharing economy. Business \& Inf. Systems Engineering, Vol. 58, No. 1, 93-99.

[31] Kathan, W.; Matzler, K. \& Veider, V. (2016). The sharing economy: your business model's friend or foe? Business Horizons, Vol. 59, No. 6, 663-672, ISSN 0007-6813.

[32] Wallenstein, J. \& Shelat, U. (2017). What's next for the sharing economy?, BCG Institute, Accessed on: 10-2017.

[33] Moeller, S. \& Wittkowski, K. (2010). The burdens of ownership: reasons for preferring renting. Managing Service Quality: An International Journal, Vol. 20, No. 2, 176 - 191, ISSN 0960-4529.

[34] DelCampo, R.; Haggerty, L.; Haney, M. \& Knippel, L. (2011). Managing the multi-generational workforce: from the GI generation to the millennials. Gower Publishing, Ltd.

[35] Mastrolia, S. \& Willits, S. (2013). Millennials: what do we really know about them? Advances in Accounting Education: Teaching and Curriculum Innovations, 45-72.

[36] Kuron, L.; Lyons, S. T.; Schweitzer, L. \& Ng, E. (2015). Millennials' work values: differences across the school to work transition. Personnel Review, 44, 991-1009.

[37] Payton, F. C. (2015). Workplace design: The Millennials are not coming - they're here. Design Man Rev, $26,54-63$.

[38] Regina E. \& Deal, J. (2017). Viewpoint - A European Perspective on Millennials, IEDP, Accessed on: 02-10-2017.

[39] Werth, E. \& Werth, L. (2011). Effective training for millennial students. Adult Learning, Vol. 22, No. 3, $12-19$.

[40] Belk, R. (2013), You are what you can access: sharing and collaborative consumption online, Journal of Business Research, Vol. 74, No. 8, 1595-1600, ISSN 0148-2963.

[41] Godelnik, R. (2017). Millennials and the sharing economy: Lessons from a "buy nothing new, share everything month" project. Environmental Innovation and Societal Transitions, 23, 40-52. doi:10.1016/j.eist.2017.02.002

[42] Wilkesmann, M. \& Wilkesmann, U. (2018). Industry 4.0 - organizing routines or innovations?. VINE Journal of Information and Knowledge Management Systems, Vol. 48, No. 2, 238-256, ISSN 2059-5891.

[43] Darnley, R.; DiPlacido, M.; Kerns, M. \& Kim, A. (2018). Industry 4.0: digitization in Danish industry, Worcester Polytechnic Institute and Copenhagen School of Entrepreneurship, No. D184.

[44] Imran, F. \& Kantola, J. (2018). Review of Industry 4.0 in the light of sociotechnical system theory and competencebased view: A future research agenda for the evolute approach, In: Proceedings of the AHFE 2018, Kantola, J.; Nazir, S. \& Barath, T. (Ed.), 118-128, Springer, ISBN 978-3-319-94709-9, Florida.

[45] Dachs, B.; Kinkel, S. \& Jäger, A. (2017). Bringing it all back home? Backshoring of manufacturing activities and the adoption of Industry 4.0 technologies. AIT \& Fraunhofer-Inst. for Syst. and Innov. Res., MPRA paper No. 83167.

[46] Müller, J.; Buliga, O. \& Voigt, K.-I. (2018). Fortune favors the prepared: how SMEs approach business model innovations in Industry 4.0. Technological Forecasting and Social Change, Vol. 132, 2-17, ISSN, 0040-1625.

[47] Valentin, B. (2017). Methods of assessment and training of a company towards the Enterprise 4.0, Proceedings of the 28th DAAAM International Symposium, ISBN 978-3-902734-11-2, ISSN 1726-9679, Katalinic, B. (Ed.), pp. 1065-1073, Published by DAAAM International, Vienna, Austria, DOI 10.2507/28th.daaam.proceedings.148. 